\title{
Prone versus supine positioning for whole and partial breast radiotherapy: a comparison of non-target tissue dosimetry
}

\author{
Kirby $\mathrm{AM}^{1}$, Evans $\mathrm{PM}^{2}$, Donovan $\mathrm{EM}^{1}$, Convery $\mathrm{HM}^{1}$, Haviland $\mathrm{JS}^{2}$, Yarnold $\mathrm{JR}^{2}$ \\ ${ }^{1}$ Royal Marsden NHS Foundation Trust, Sutton, UK and ${ }^{2}$ Institute of Cancer Research, Sutton, UK
}

Corresponding author: Dr Anna M. Kirby FRCR, Department of Academic Radiotherapy, Royal Marsden NHS Foundation Trust, Downs Road, Sutton, Surrey, SM2 5PT, United Kingdom. Telephone: +44 208661 3169. Fax: +44 208661 3107. E-mail: anna.kirby@rmh.nhs.uk

Acknowledgements: Dr A Kirby was funded by a Royal College of Radiologists' Clinical Oncology Research Fellowship and by the Breast Cancer Research Trust. The authors are grateful to Mr Craig Cummings in the Institute of Cancer Research Workshop for his assistance in the design and manufacture of the prone breast platform. The work was undertaken in The Royal Marsden NHS Foundation Trust which receives a proportion of its funding from the NHS Executive; the views expressed in this publication are those of the authors and not necessarily those of the NHS Executive.

Key words: Breast cancer; Prone breast radiotherapy; Partial breast irradiation; Cardiac dosimetry

Conflict of interest: None declared. 


\section{Abstract}

Purpose: To compare non-target tissue (including left-anterior-descending coronary-artery (LAD)) dosimetry of whole $(\mathrm{WBI})$ and partial-breast irradiation $(\mathrm{PBI})$ planned in prone versus supine positions.

Methods and materials: Sixty-five post-lumpectomy breast cancer patients underwent CTimaging supine and prone. On each dataset, whole-breast clinical-target-volume (CTV) was defined using wire and partial-breast CTV as tumour-bed $+15 \mathrm{~mm}$. Heart and LAD were outlined in left-breast-affected patients $(n=30)$, and ipsilateral lung and chest-wall in all patients. Tangentialfield WBI and PBI plans were generated for each position. Mean LAD, heart, and ipsilateral lung doses $\left(\mathrm{NTD}_{\text {mean }}\right)$, maximum LAD $\left(\mathrm{LAD}_{\max }\right)$ doses, and chest-wall $\mathrm{V}_{50 \mathrm{~Gy}}$ were compared.

Results: 260 plans were generated. Prone positioning reduced heart and LAD doses in 19/30 WBI cases (mean reduction in $L A D-N T D_{\text {mean }}=7.5 \mathrm{~Gy}$ ) and $7 / 30 \mathrm{PBI}$ cases (mean reduction in $\mathrm{LAD}_{\text {max }}$ $=27.6 \mathrm{~Gy}$ ). However, prone positioning increased cardiac doses in $8 / 30 \mathrm{WBI}$ (mean increase in LAD-NTD $D_{\text {mean }}=8.4 G y$ ) and $19 / 30 \mathrm{PBI}$ cases (mean increase in $\mathrm{LAD}_{\max }=23.7 \mathrm{~Gy}$ ). WBCTV $>1000 \mathrm{~cm}^{3}$ was associated with improved cardiac dosimetry in the prone position for WBI $(p=0.04)$ and PBI $(p=0.02)$. Prone positioning reduced ipsilateral-lung $N T D_{\text {mean }}$ in $65 / 65 \mathrm{WBI}$ and 61/65 PBI cases, and chest-wall $\mathrm{V}_{50 \mathrm{G}}$ in all $\mathrm{WBI}$ cases. PBI reduced normal-tissue doses compared to WBI in all cases, regardless of treatment position.

Conclusions: In the context of tangential-field WBI and PBI, prone positioning is likely to benefit left-breast-affected women of cup-size $\geq D$, and most right-breast-affected women, but to be detrimental in left-breast-affected women of smaller cup size. PBI reliably reduces normal-tissue doses compared to WBI such that eligible women should be encouraged to participate in PBI studies. 


\section{Introduction}

Whole-breast irradiation (WBI) following breast-conserving surgery (BCS) improves local control and survival from breast cancer but increases non-breast-cancer-related deaths by $1 \%$ at 15 years (1). The majority of these deaths are cardiovascular in origin (2) and irradiation of the left-anteriordescending coronary-artery (LAD) is implicated in pathogenesis (3-5). Irradiation of lung, chestwall and other tissues also contributes to late mortality and morbidity $(1,2)$. Improvements in radiotherapy techniques have resulted in reduced normal-tissue doses (6), correlating with reduced non-breast-cancer-related mortality (2). Nonetheless doses to the heart, LAD and lung from current standard supine WBI remain significant (7).

Methods by which normal-tissue doses could be decreased include optimization of patient positioning and use of partial-breast irradiation (PBI). Prone positioning for WBI improves dose homogeneity within breast-tissue $(8,9)$, reduces lung doses (10-12), and reduces wedge requirements with consequent reduction of scattered dose, particularly in women of larger cup-size (10). However, reports comparing cardiac dosimetry from supine versus prone WBI are conflicting. One study using IMRT (13) reported that prone positioning reduced within-field heart volume in $85 \%$ of women. However, studies using conventional tangential-field arrangements have failed to show an overall benefit of prone positioning on cardiac dosimetry $(11,14)$. Furthermore, a study comparing distances between anterior pericardium and chest-wall on supine CT-images and prone MRI (15) found prone positioning to systematically displace supero-lateral aspects of heart-tissue closer to chest-wall, such that prone positioning might be detrimental where target tissues include chest-wall and/or deeply-lying breast tissue. Thus far, LAD doses from prone positioning have not been documented.

PBI could also reduce normal-tissue doses by restricting higher radiation doses to the volume of breast tissue at highest risk of tumour relapse (16). The combination of prone positioning and PBI is particularly attractive in terms of reducing normal-tissue toxicity. A dosimetric comparison of accelerated PBI techniques (14) found that brachytherapy \& prone tomotherapy resulted in least 
dose to lung and non-target ipsilateral breast tissue (compared with supine 3D-conformal-RT and tomotherapy). However, heart doses again varied between patients, prone tomotherapy benefiting only women with larger breasts and/or lesions further from chest-wall.

Cardiac and, in particular, LAD dosimetry from prone $\mathrm{WBI}$ and $\mathrm{PBI}$ require further evaluation before prone positioning can be adopted into routine practice. As the majority of centres worldwide continue to use conventional tangential-field arrangements, this study prospectively evaluates nontarget tissue exposure from WBI and PBI planned conventionally in supine and prone positions using within-patient comparison. The resulting four-way comparison of prone and supine, WBI and PBI aims to clarify optimal approaches to reducing normal-tissue exposure applicable to the majority of current practices.

\section{Methods and materials}

This study was approved by the Royal Marsden Committee for Clinical Research and the Regional Ethics Committee. All women had undergone BCS for unifocal T1-2 G1-3 invasive-ductal carcinoma or high-grade ductal-carcinoma-in-situ, at which time titanium-clips were placed in the tumour-bed (TB) according to a UK protocol (17).

\section{Patient positioning and image acquisition}

Patients underwent non-contrast CT-imaging (slice-thickness $1.5 \mathrm{~mm}$, C6 to below diaphragm) in the standard supine position at which time radio-opaque wire was placed at the palpable edge of breast-tissue circumferentially. Patients were repositioned and CT-imaged prone using an inhouse-designed platform, with an aperture through which index-breast could fall away from chestwall [Figure 1]. Radio-opaque wire remained in-situ for prone CT-imaging.

Target and non-target tissue delineation

Whole-breast (WB) clinical-target-volume (CTV) was defined using wire plus any additional breasttissue visualized on $\mathrm{CT}$, limited by $5 \mathrm{~mm}$ from skin and chest-wall/lung interfaces. Partial-breast CTV was defined as TB (clips plus seroma and/or architectural distortion) expanded by 15mm in 3- 
D (limited circumferentially by WB-CTV). Planning-target-volumes (PTV) were generated by addition of 3-D $10 \mathrm{~mm}$ margins to CTV, limited by $5 \mathrm{~mm}$ from skin.

Heart and LAD were defined according to published criteria (6). Where LAD was difficult to visualise, its location was inferred from the course of the anterior-interventricular groove (6). Consistent with previous practice, an $10 \mathrm{~mm}$ axial margin was added to the LAD to allow for delineation-uncertainty, respiratory-motion and cardiac-motion (7). Ipsilateral-lung was outlined using an autocontour tool (edited to exclude major airways). Chest-wall was defined as ipsilateral ribcage and intercostal musculature.

\section{Radiotherapy-planning}

For each position, standard opposing tangential-fields were employed such that for $\mathrm{WBI}, \geq 90 \%$ of WB-CTV was encompassed by the $95 \%$-isodose and, for PBI, $\geq 95 \%$ of partial-breast CTV was encompassed by the $95 \%$-isodose (according to UK National-Cancer-Research-Institute IntensityModulated Partial Organ Radiotherapy (IMPORT) study criteria (18)). Plans fulfilled ICRU dosehomogeneity criteria (19). Dose-distributions were reviewed in 3D and using dose-volumehistogram (DVH) data. 50Gy in 25 fractions over 5 weeks (6-10MV photons) was prescribed to the $100 \%$ isodose. MLC leaves were used as required to reduce cardiac doses whilst maintaining satisfactory coverage of WB and PB-CTVs as defined above.

\section{Analysis}

$\mathrm{NTD}_{\text {mean }}$ (a biologically-weighted mean of dose to normal-tissue normalised to 2Gy fractions (20)) was calculated for heart, $L A D$, and lung. Maximum-dose to $L A D\left(L A D_{\max }\right)$ was read from $D V H$ data. The volume of chest-wall receiving 50Gy $\left(\mathrm{V}_{50 \mathrm{G} y}\right)$ was calculated.

Differences between heart, LAD and lung-NTD $D_{\text {mean }}, L A D_{\max }$, and chest-wall $\mathrm{V}_{50 \mathrm{~Gy}}$ for supine versus prone $\mathrm{WBI}$, supine versus prone $\mathrm{PBI}$, and supine $\mathrm{WBI}$ versus $\mathrm{PBI}$ plans were calculated for each patient and compared using the paired t-test or Wilcoxon signed-rank test, as appropriate. Lung and chest-wall doses were compared in all patients. Cardiac doses were compared for left-breastaffected patients only (as a population and by individual patient). Individual-patient cardiac data 
were pooled by WB-CTV into tertiles $\left(\leq 500 \mathrm{~cm}^{3}, 501-1000 \mathrm{~cm}^{3},>1000 \mathrm{~cm}^{3}\right)$ and the likelihood of benefit from prone positioning compared between tertiles using analysis-of-variance.

\section{Results}

65 women were recruited (30 left-sided: 35 right-sided BC). Mean age was 57 years (range 34-79 years). Self-reported cup-sizes and WB-CTVs are illustrated in figure 2. There was no difference between WB-CTVs delineated in supine and prone positions $(p=0.15)$. Satisfactory coverage of target-volumes was achieved in $100 \%$ of plans.

\section{Cardiac dosimetry}

Heart and LAD doses for the patients with left BC (30 cases, 120 plans) are summarized in table 1 and figure 3. Overall, for the population of left-breast-affected women, there was no significant difference in cardiac parameters between prone and supine positions for either WBI or PBI.

Comparing doses within patients, for WBI prone positioning was advantageous in 19/30 patients but disadvantageous in 8/30 patients. The magnitude of the difference between LAD-NTD mean doses was similar whether prone positioning improved or worsened dosimetry [table 2]. In 3/30 patients, prone positioning increased LAD-NTD mean but decreased $L A D_{\text {max }}$. If heart-NTD mean had been the only comparator, $20 / 30$ would have been judged to benefit from prone and 10/30 from supine positioning.

For $\mathrm{PBI}$, prone positioning was advantageous in $7 / 30$ patients, and disadvantageous in 19/30 patients. The magnitude of the difference between $L A D_{\max }$ doses was similar whether prone positioning improved or worsened dosimetry. In 4/30 cases, parameters failed to agree on optimal position. If heart NTD mean had been the only comparator, $13 / 30$ patients would have been judged to benefit from prone and 17/30 from supine positioning.

Across all 60 WBI-plans for left-breast-affected cases, $L A D_{\max }$ was high ( $\geq 29.9 \mathrm{~Gy}$ ) irrespective of treatment position. The mean difference in $L A D_{\max }$ for prone versus supine $W B I$ was $4.5 \pm 2.5 \mathrm{~Gy}$. There was greater inter-patient variability in LAD NTD mean (mean difference in prone versus supine LAD-NTD ${ }_{\text {mean }}=7.7 \pm 2.3 G y_{3}$ ). Conversely, across all $60 \mathrm{PBI}$ plans, LAD-NTD mean was low (mean 
LAD-NTD $D_{\text {mean }}=2.8 \pm 2.5 \mathrm{~Gy}_{3}$ ) with a mean difference in prone versus supine $L A D-N T D_{\text {mean }}$ of 2.6 $\pm 1.2 G y_{3}$. There was greater inter-patient variability in $L A D_{\max }$ (mean difference in prone versus supine $\left.L A D_{\max }=25.7 \pm 8.5 \mathrm{~Gy}\right)$. There was a correlation between heart- and $L A D-N T D_{\text {mean }}(R=0.80$ for WBI, $p=0.01 ; R=0.67$ for $\mathrm{PBI}, \mathrm{p}=0.01)$, and between heart-NTD mean and $\mathrm{LAD}_{\max }(\mathrm{R}=0.44$ for WBI, $p=0.01 ; R=0.59$ for $\mathrm{PBI}, \mathrm{p}=0.01)$.

Analysing results by volumetric-tertile, for WBI there was a significant benefit of prone positioning on cardiac doses for women with breast volumes $>1000 \mathrm{~cm}^{3}(p=0.04)$ [figure 4]. All women of D-cup or above benefited from the prone position with the exception of one patient (G cup) whose TB was in the axillary-tail. In the context of $\mathrm{PBI}$, there was a significant benefit of prone positioning on $\operatorname{LAD}_{\max }$ doses $(p=0.02)$ but not on heart- $(p=0.09)$ or LAD-NTD mean $(p=0.14)$ doses for women with breast-volumes $>1000 \mathrm{~cm}^{3}$. A breast volume of $\leq 1000 \mathrm{~cm}^{3}$ was significantly associated with a benefit from supine positioning in the context of both WBI and PBI.

Figure 5 demonstrates that in both small- and large-breasted women, heart-tissue moves anteriorly in relation to chest-wall. However, the larger breast is pulled further anteriorly than the smaller breast owing to the greater weight of breast-tissue such that shallower tangents can be placed thereby sparing a greater volume of normal-tissue.

Cardiac doses were significantly lower for $\mathrm{PBI}$ as compared to WBI $(\mathrm{p}<0.001)$. Mean reductions in heart-NTD $D_{\text {mean }}$ were $0.7 \pm 0.1 \mathrm{~Gy}_{3}$ (supine) and $0.5 \pm 0.1 \mathrm{~Gy} y_{3}$ (prone). Mean reductions in LAD-NTD mean were $9.4 \pm 0.2 \mathrm{~Gy}_{3}$ (supine) and $6.1 \pm 1.5 \mathrm{~Gy}_{3}$ (prone). Mean reductions in $\mathrm{LAD}_{\max }$ were $22.7 \pm 6.2 \mathrm{~Gy}$ (supine) and 11.9 $\pm 5.4 \mathrm{~Gy}$ (prone).

\section{Lung and chest-wall dosimetry}

Ipsilateral-lung NTD mean doses (65 cases, 260 plans) are summarised in table 1 and figure $3 \mathrm{~d}$. Prone, as compared to supine, positioning significantly reduced ipsilateral-lung NTD $_{\text {mean }}$ in $65 / 65$ WBI cases (mean reduction=3.5 $\pm 0.5 \mathrm{~Gy}_{3}(\mathrm{p}<0.001)$ ), and 61/65 PBI cases (mean reduction= $1.1 \pm 0.2 \mathrm{~Gy}_{3}(\mathrm{p}<0.001)$. In $4 / 65 \mathrm{PBI}$ cases, ipsilateral-lung-NTD $\mathrm{N}_{\text {mean }}$ was similar in both positions because TBs were located at the lateral edge of breast-tissue such that PB-CTV coverage would 
have been compromised by shallower tangents in the prone position. Ipsilateral-lung NTD mean was significantly lower for $\mathrm{PBI}$ as compared to $\mathrm{WBI}$ (mean reduction $=2.9 \pm 0.3 \mathrm{~Gy} \mathrm{y}_{3}$ (supine) and $0.4 \pm 0.1 \mathrm{~Gy}_{3}$ (prone) $\left.(\mathrm{p}<0.001)\right)$.

Prone positioning significantly reduced chest-wall $\mathrm{V}_{50 \mathrm{~Gy}}$ for WBI only (table 1 , figure $3 e$ ). Use of supine $\mathrm{PBI}$, compared to $\mathrm{WBI}$, reduced chest-wall $\mathrm{V}_{50 \mathrm{~Gy}}$ by $17 \pm 7 \mathrm{~cm}^{3}(p<0.001)$. There was no difference between chest-wall $V_{50 G y}$ for prone PBI versus WBI $(p=0.08)$.

\section{Discussion}

This study aimed to compare normal-tissue (including left-anterior-descending coronary-artery (LAD)) dosimetry from conventional tangential-field whole- and partial-breast radiotherapy planned in prone versus supine positions.

\section{Cardiac dosimetry}

We found the effects of prone positioning upon both heart and LAD doses to be variable between patients, consistent with previous studies $(10,14)$. Around two-thirds of patients planned for WBI benefited from prone positioning, with mean improvements in heart-NTD mean, LAD-NTD mean and $L A D_{\max }$ of $0.4 \mathrm{~Gy}, 7.0 \mathrm{~Gy}$ and 4.9Gy respectively. However, in a third of patients, prone positioning would have increased cardiac doses to a similar extent (table 2). Only a quarter of patients planned for PBI would have benefited from prone positioning, with mean improvements in heart$\mathrm{NTD}_{\text {mean }}, \mathrm{LAD}-\mathrm{NTD}_{\text {mean }}$ and $\mathrm{LAD}_{\text {max }}$ of $0.2 \mathrm{~Gy}, 2.1 \mathrm{~Gy}$, and 27.6Gy respectively. In two-thirds of PBI cases, prone positioning would have increased cardiac doses to a similar extent (table 2).

We found a significant benefit of prone positioning upon heart/LAD doses for women of WBCTV $>1000 \mathrm{~cm}^{3}$ (equivalent to UK cup size $\geq$ D) for both WBI and PBI, consistent with previous work reporting a trend towards a significant benefit of prone positioning upon heart dose in women of breast cup-size $\geq E(11)$. Our findings are also consistent with work reporting that heart-tissue moves towards chest-wall in patients positioned prone (15). Only patients in whom breast-tissue falls anteriorly in relation to chest-wall in the prone position (such that shallower tangents can be 
placed) are likely to gain from prone treatment. Otherwise, where smaller breasts are not pulled anteriorly, tangents are likely to encompass more cardiac tissue in the prone position.

Not all patients of large breast size in our study had better cardiac dosimetry in the prone position. One patient (cup size $\mathrm{G}$ ) had a tumour-bed in the axillary tail which could not be encompassed by WBI-tangents without increasing their depth and therefore normal-tissue doses. There may be other predictive factors including heart-size, chest-wall breadth and curvature that our study is underpowered to detect.

The proportion of women benefitting from prone positioning in our study differed from interim reports of the largest ongoing comparative study of prone versus supine $\mathrm{WBI}$, which suggest that prone positioning reduces in-field heart volume in the majority (85\%) of left-sided BC patients $(n=200)(13)$. Discrepancies between results could be due to use of volumetric rather than dosimetric comparators and/or to use of IMRT rather than conventional tangential-fields. Using IMRT, an in-field heart volume of $0 \mathrm{~cm}^{3}$ is likely to be achievable in a proportion of patients in both supine and prone positions. In this case, the effect of prone positioning upon heart is assumed to be neutral but the prone position might still be judged "optimal" based on reduced in-field lung volume compared to the supine position. This approach does not however detect differences in lower-dose irradiation of cardiac tissues thereby overestimating the clinical benefits of prone positioning in comparison to our study. Our additional use of LAD-dosimetry to discern optimal treatment position might also have lead to differing results. Although heart- and LAD-NTD mean correlated reasonably well, there was disagreement between heart and LAD doses over optimal treatment position in $7 / 60$ plans. Had heart $N T D_{\text {mean }}$ been the only comparator, $20 / 30$ and $13 / 30$ patients would have benefited from prone treatment in the context of WBI and PBI respectively. Another source of discrepancies could be the method by which WB-CTV is defined. Clinicians' decisions on where to place the posterior RT-field border in order to achieve target-volume coverage will significantly impact upon doses to tissues close to chest-wall. Our study used a method of WB-CTV definition agreed to be more representative of the true volume than standard 
anatomical landmarks (21). Wire-delineated breast tissue shifts anteriorly in the prone position but is consistently included as WB-CTV. Our WB-CTVs were comparable between positions with no significant difference in percentage volume covered. Additionally, all of our cases had titanium-clipdefined TB volumes, without which, coverage of PB-CTV at depth cannot be ensured (22).

The clinical impact of differences in cardiac doses of the magnitude described above is difficult to quantify as radiation parameters determining excess cardiovascular disease (CVD) risk are poorly understood. Gagliardi (23) used the relative-seriality model to quantitatively describe the doseresponse relationship for excess cardiac mortality and found a low dependence of this endpoint upon irradiated-heart-volume, concluding that cardiac mortality is more likely to be reduced by decreasing dose than by restricting irradiated volume. Borger et al (24) also found no relationship between maximum heart distance (MHD) (a correlate of irradiated-heart-volume) and risk of CVD but reported that, even where $\mathrm{MHD}=0 \mathrm{~mm}$, more cardiotoxic effects occurred following left-sided as compared to right-sided-RT suggesting that differences in doses < $25 \mathrm{~Gy}$ may be important. Other data supporting the hypothesis that low-dose radiation increases CVD risk come from atomicbomb survivors (4Gy single exposure) (25), patients treated with RT for peptic-ulcer disease (mean heart dose 1.6-3.9Gy) (26), patients treated with para-aortic irradiation for testicular cancer ( 1Gy scattered heart dose) (27) and radiation workers (28). Cardiac variables which encompass volumes of cardiac tissue irradiated to low doses such as heart-NTD mean have shown a strong correlation with mortality (29). Optimal positioning in our study decreased mean heart-NTD mean from $\sim 1.2$ to $\sim 0.8 \mathrm{~Gy} y_{3}$ for $\mathrm{WBI}$, and from $\sim 0.5$ to $\sim 0.3 \mathrm{~Gy}{ }_{3}$ for PBI. Based on the evidence above, the risks of low-dose cardiac irradiation are not negligible. However, the dose-effect relationship at these dose-levels is difficult to define and the clinical consequences of such small differences unquantifiable.

Meanwhile, other studies suggest that LAD dose is the most relevant exposure variable (3-5). Retrospective review of patients irradiated between 1977-95 found a significantly higher prevalence of cardiac stress-test abnormalities amongst left- versus right-side-irradiated patients, 
$70 \%$ of which were in LAD territory (3) CHECK Others correlate a fall in mean LAD doses from breast RT over the last 30 years $(6,7)$ with a decrease in CVD over the same period (2). Furthermore, it may be that Gagliardi's finding of a low dependence of cardiac mortality upon irradiated-heart-volume (23) relates to the fact that the LAD is likely to remain within the high-dose volume from a tangential-field arrangement even at low irradiated-heart-volumes. Optimal positioning in our study decreased mean LAD-NTD mean from $\sim 14 G y$ to 6 Gy for WBI, and from $\sim 4 G y$ to $1.5 \mathrm{~Gy}$ for PBI. Reductions in dose of these magnitudes could be associated with a significant reduction in CVD (7). As atherosclerosis anywhere along the LAD could cause CVD, $L A D_{\max }$ is a relevant additional variable. Optimal positioning in our study decreased mean $L A D_{\max }$ from $\sim 49 G y$ to $45 \mathrm{~Gy}$ for $\mathrm{WBI}$, and from $42 \mathrm{~Gy}$ to $15 \mathrm{~Gy}$ for $\mathrm{PBI}$. The latter could be particularly significant depending partly upon the threshold dose for atherosclerosis, Gagliardi's work suggesting that the risk of cardiac mortality rises steeply above doses of around 20Gy regardless of the volume irradiated (23). Whether dosimetric differences of these magnitudes continue to be relevant in the context of $5 \mathrm{~mm}$ set-up errors and physiological changes in heart and intra-thoracic volume with respiration (each of which may cause interfraction variations in normal-tissue doses) remains to be determined.

\section{Lung and chest-wall dosimetry}

Our study confirms previous reports (10-12) that prone positioning reduces mean lung doses for both WBI and PBI and furthermore demonstrates that benefits are applicable to women of all cupsizes. The main threat of death in relation to irradiation of lung-tissue is from low-dose stochastic effects rather than from high-dose deterministic effects, the relative-risk of death from secondprimary lung cancer ranging from 1.5 to 2.8 at 15 years $(30,31)$, with odds ratios of up to 37.6 reported in smokers (32). Data on lung-cancer deaths in 9000 women irradiated in 1935-1971 (30) suggest a dose-response relationship with an incremental RR of 0.2 per Gy to ipsilateral-lung (equating to 9 cases of RT-induced lung cancer/ year/10,000 women receiving a lung dose of 10Gy and living to 10 years). The SEER registry cohort demonstrates a similar relationship 
between mean lung dose and risk of second-primary lung-cancer (2) in women irradiated in 19732001. Our mean lung-NTD mean for supine WBI was 3.7Gy. Prone positioning reduced this to 0.3Gy. Based on evidence above, this reduction in dose might prevent around 3 lung cancers/year/10000 women living to 10 years post-RT. The effect may be larger however in women who smoke, in whom prone treatment might be particularly beneficial.

The START trial suggests that $40 \%$ of women experience chest-wall discomfort at 10 years postRT (33), whilst the incidence of rib-fracture following WBI is reported to be $0.3-2.2 \%(34,35)$. A recent study of external-beam-accelerated-PBI found the incidence of chest-wall pain and rib fracture to relate to the volume of chest-wall receiving $35 \mathrm{~Gy}$ or more (based on $38.5 \mathrm{~Gy} / 10$ fractions 5 days (36)). This is equivalent to around 48Gy in 2 Gy fractions and is in keeping with tolerance doses published by Emami (37) ( $T D_{5 / 5}$ ribcage $\sim 50 \mathrm{~Gy}$ ). Therefore chest-wall $\mathrm{V}_{50 \mathrm{~Gy}}$ could be considered a reasonable parameter by which to compare radiotherapeutic approaches in terms of late chest-wall discomfort. Prone positioning significantly reduces chest-wall $\mathrm{V}_{50 \mathrm{G} y}$ in $\mathrm{WBI}$ and therefore warrants consideration as a technique by which chest-wall morbidity might be reduced.

\section{The future of prone breast $R T$}

In departments where conventional tangential-field WBI is standard, prone positioning is likely to benefit most left-breast-affected women of cup size $\geq D$, and nearly all right-breast-affected women. A current priority is to establish whether or not the position is reproducible in order that dosimetric benefits can be realized. In the context of tangential-field PBI, prone positioning benefited fewer left-breast-affected women but still reduced the $L A D_{\max }$ by over 20Gy in many large-breasted women. Further work in this setting might be helpful in establishing predictive factors for deciding optimal treatment position in left-breast-affected women. For right-breast-affected women, reductions in lung and chest wall doses are small and a change of treatment technique may not therefore be warranted. Based on our results, prone positioning for either WBI or PBI is not recommended in left-breast-affected women of cup-size $<\mathrm{C}$ as cardiac doses may be significantly increased in comparison to supine treatment. 


\section{$P B I$ versus $W B I$}

The normal-tissue dosimetric advantages of PBI have been assumed but not proven. Indeed a recent study reported that $3 \mathrm{D}$-conformal $\mathrm{PBI}$ increased the volume of lung exposed to low-dose radiation whilst decreasing the volume of tissue exposed to higher-dose radiation (38). We found that supine PBI reduced mean heart-NTD mean (by $0.6 \mathrm{~Gy}$ ), mean LAD-NTD mean $(9 \mathrm{~Gy})$, mean $\mathrm{LAD}_{\text {max }}$ (23Gy), mean ipsilateral-lung-NTD mean (3Gy) and mean chest-wall $V_{50 G y}\left(17 \mathrm{~cm}^{3}\right)$ compared to supine WBI. With dose-sparing of this magnitude, it seems likely that PBI will reduce long-term cardiovascular side-effects of breast RT, reduce second-primary lung malignancies by around 2 lung cancers/year/10000 women at 10 years post-RT, and reduce the incidence of late chest-wall discomfort. PBI should be considered the optimal strategy for reducing late morbidity of breast RT but is currently only available in trials for which many women are ineligible. Prone positioning still has a role in reducing normal-tissue toxicity in women requiring adjuvant WBI.

\section{Conclusions}

In the context of tangential-field $\mathrm{WBI}$ and $\mathrm{PBI}$, prone positioning is likely to benefit left-breastaffected women of cup-size $\geq D$, and most right-breast-affected women, but to be detrimental in left-breast-affected women of smaller cup size. PBI reliably reduces normal-tissue doses compared to WBI such that eligible women should be encouraged to participate in PBI studies. 


\section{References}

1. Clarke M, Collins R, Darby S, et al. Effects of radiotherapy and of differences in the extent of surgery for early breast cancer on local recurrence and 15-year survival: an overview of the randomised trials. Lancet 2005;366:2087-2106.

2. Darby SC, McGale P, Taylor CW, et al. Long-term mortality from heart disease and lung cancer after radiotherapy for early breast cancer: prospective cohort study of about 300,000 women in US SEER cancer registries. Lancet Oncol 2005;6:557-565.

3. Correa CR, Das IJ, Litt HI, et al. Association between tangential beam treatment parameters and cardiac abnormalities after definitive radiation treatment for left-sided breast cancer. Int J Radiat Oncol Biol Phys 2008;72:508-516.

4. Storey MR, Munden R, Strom EA, et al. Coronary artery dosimetry in intact left breast irradiation. Cancer J 2001;7:492-497.

5. Lind PA, Pagnanelli R, Marks LB, et al. Myocardial perfusion changes in patients irradiated for left-sided breast cancer and correlation with coronary artery distribution. Int $J$ Radiat Oncol Biol Phys 2003;55:914-920.

6. Taylor CW, Nisbet A, McGale P, et al. Cardiac exposures in breast cancer radiotherapy: 1950s-1990s. Int J Radiat Oncol Biol Phys 2007;69:1484-1495.

7. Taylor CW, Povall JM, McGale P, et al. Cardiac dose from tangential breast cancer radiotherapy in the year 2006. Int J Radiat Oncol Biol Phys 2008;72:501-507.

8. Merchant TE, McCormick B. Prone position breast irradiation. Int J Radiat Oncol Biol Phys 1994;30:197-203.

9. Grann A, McCormick B, Chabner ES, et al. Prone breast radiotherapy in early-stage breast cancer: a preliminary analysis. Int J Radiat Oncol Biol Phys 2000;47:319-325.

10. Griem KL, Fetherston $\mathrm{P}$, Kuznetsova $\mathrm{M}$, et al. Three-dimensional photon dosimetry: a comparison of treatment of the intact breast in the supine and prone position. Int $J$ Radiat Oncol Biol Phys 2003;57:891-899. 
11. Buijsen $\mathrm{J}$, Jager $\mathrm{JJ}$, Bovendeerd $\mathrm{J}$, et al. Prone breast irradiation for pendulous breasts. Radiother Oncol 2007;82:337-340.

12. DeWyngaert JK, Jozsef G, Mitchell J, et al. Accelerated intensity-modulated radiotherapy to breast in prone position: dosimetric results. Int J Radiat Oncol Biol Phys 2007;68:12511259.

13. Formenti S, Lymberis S, Parhar P, Fenton-Kerimian M, Magnolfi C, Wen B, Chang J, DeWyngaert J. Results of NYU 05-181: A prospective trial to determine optimal position (prone versus supine) for breast radiotherapy. Int J Radiat Biol 2009;75:S203-S204.

14. Patel RR, Becker SJ, Das RK, et al. A dosimetric comparison of accelerated partial breast irradiation techniques: multicatheter interstitial brachytherapy, three-dimensional conformal radiotherapy, and supine versus prone helical tomotherapy. Int $J$ Radiat Oncol Biol Phys 2007;68:935-942.

15. Chino JP, Marks LB. Prone positioning causes the heart to be displaced anteriorly within the thorax: implications for breast cancer treatment. Int J Radiat Oncol Biol Phys 2008;70:916920.

16. Smith TE, Lee D, Turner BC, et al. True recurrence vs. new primary ipsilateral breast tumor relapse: an analysis of clinical and pathologic differences and their implications in natural history, prognoses, and therapeutic management. Int $J$ Radiat Oncol Biol Phys 2000;48:1281-1289.

17. Coles $\mathrm{CE}$, Wilson $\mathrm{CB}$, Cumming J, et al. Titanium clip placement to allow accurate tumour bed localisation following breast conserving surgery: audit on behalf of the IMPORT Trial Management Group. Eur J Surg Oncol 2009;35:578-582.

18. Yarnold, J, Coles, C. On behalf of the IMPORT-Low Trial Management Group. IntensityModulated and Partial Organ Radiotherapy. Randomised trial testing intensity-modulated and partial organ radiotherapy following breast conservation surgery for early breast cancer. Trial Protocol, version 4. Institute of Cancer Research, Sutton, UK. p.1-74. 
19. ICRU Report 62. Prescribing, Recording and Reporting Photon Beam Therapy (Supplement to ICRU Report 50). Maryland:Bethseda; 1999.

20. Scrimger RA, Tome WA, Olivera $\mathrm{GH}$, et al. Reduction in radiation dose to lung and other normal tissues using helical tomotherapy to treat lung cancer, in comparison to conventional field arrangements. Am J Clin Oncol 2003;26:70-78.

21. Valdagni $\mathrm{R}$, Italia $\mathrm{C}$, Montanaro $\mathrm{P}$, et al. Clinical target volume localization using conventional methods (anatomy and palpation) and ultrasonography in early breast cancer post-operative external irradiation. Radiother Oncol 1997;42:231-237.

22. Algan O, Fowble B, McNeeley S, et al. Use of the prone position in radiation treatment for women with early stage breast cancer. Int J Radiat Oncol Biol Phys 1998;40:1137-1140.

23. Gagliardi G, Lax I, Ottolenghi A, et al. Long-term cardiac mortality after radiotherapy of breast cancer--application of the relative seriality model. Br J Radiol 1996;69:839-846.

24. Borger $\mathrm{JH}$, Hooning $\mathrm{MJ}$, Boersma LJ, et al. Cardiotoxic effects of tangential breast irradiation in early breast cancer patients: the role of irradiated heart volume. Int $J$ Radiat Oncol Biol Phys 2007;69:1131-1138.

25. Preston DL, Shimizu Y, Pierce DA, et al. Studies of mortality of atomic bomb survivors. Report 13: Solid cancer and noncancer disease mortality: 1950-1997. Radiat Res 2003;160:381-407.

26. Carr ZA, Land CE, Kleinerman RA, et al. Coronary heart disease after radiotherapy for peptic ulcer disease. Int J Radiat Oncol Biol Phys 2005;61:842-850.

27. van den Belt-Dusebout AW, Nuver J, de Wit R, et al. Long-term risk of cardiovascular disease in 5-year survivors of testicular cancer. J Clin Oncol 2006;24:467-475.

28. McGale P, Darby SC. Low doses of ionizing radiation and circulatory diseases: a systematic review of the published epidemiological evidence. Radiat Res 2005;163:247-257.

29. Perman M, Johanson, I, Ohlson, B, Johansson, KA, Karlsson, P. Death from ischaemic heart disease 10-19 years after treatment for early breast cancer: a population-based 
nested case-control study regarding absorbed dose to the heart and 11 anatomical substructures of the heart. Radiother Oncol 2008;x:x.

30. Inskip PD, Stovall M, Flannery JT. Lung cancer risk and radiation dose among women treated for breast cancer. J Natl Cancer Inst 1994;86:983-988.

31. Roychoudhuri R, Evans $H$, Robinson D, et al. Radiation-induced malignancies following radiotherapy for breast cancer. Br J Cancer 2004;91:868-872.

32. Kaufman EL, Jacobson JS, Hershman DL, et al. Effect of breast cancer radiotherapy and cigarette smoking on risk of second primary lung cancer. J Clin Oncol 2008;26:392-398.

33. Bentzen SM, Agrawal RK, Aird EG, et al. The UK Standardisation of Breast Radiotherapy (START) Trial A of radiotherapy hypofractionation for treatment of early breast cancer: a randomised trial. Lancet Oncol 2008;9:331-341.

34. Pierce SM, Recht $\mathrm{A}$, Lingos $\mathrm{TI}$, et al. Long-term radiation complications following conservative surgery (CS) and radiation therapy (RT) in patients with early stage breast cancer. Int J Radiat Oncol Biol Phys 1992;23:915-923.

35. Meric F, Buchholz TA, Mirza NQ, et al. Long-term complications associated with breastconservation surgery and radiotherapy. Ann Surg Oncol 2002;9:543-549.

36. Reeder R, Carter DL, Howell K, et al. Predictors for clinical outcomes after accelerated partial breast intensity-modulated radiotherapy. Int J Radiat Oncol Biol Phys 2009;74:92-97.

37. Emami B, Lyman J, Brown A, et al. Tolerance of normal tissue to therapeutic irradiation. Int J Radiat Oncol Biol Phys 1991;21:109-122.

38. Jain AK, Vallow LA, Gale AA, et al. Does three-dimensional external beam partial breast irradiation spare lung tissue compared with standard whole breast irradiation? Int $J$ Radiat Oncol Biol Phys 2009;75:82-88. 
Table 1. Mean normal tissue doses (with $95 \%$ confidence intervals)

\begin{tabular}{|c|c|c|c|c|c|c|c|c|}
\hline & $\begin{array}{l}\text { Supine } \\
\text { WBI }\end{array}$ & $\begin{array}{l}\text { Prone } \\
\text { WBI }\end{array}$ & $\begin{array}{l}\text { Difference } \\
\text { between } \\
\text { prone \& } \\
\text { supine } \\
\text { WBI }\end{array}$ & $\mathbf{p}$ & $\begin{array}{l}\text { Supine } \\
\text { PBI }\end{array}$ & $\begin{array}{l}\text { Prone } \\
\text { PBI }\end{array}$ & $\begin{array}{l}\text { Difference } \\
\text { between } \\
\text { prone \& } \\
\text { supine } \\
\text { PBI }\end{array}$ & $p$ \\
\hline $\begin{array}{l}\text { Heart-NTD } D_{\text {mean }} \\
\left(G y_{3}\right)\end{array}$ & $1.0 \pm 0.1$ & $0.9 \pm 0.1$ & $0.1 \pm 0.2$ & 0.14 & $0.4 \pm 0.1$ & $0.4 \pm 0.1$ & $0.1 \pm 0.1$ & 0.08 \\
\hline $\begin{array}{l}\text { LAD-NTD }_{\text {mean }} \\
\left(\mathrm{Gy}_{3}\right)\end{array}$ & $11.5 \pm 2.3$ & $9.6 \pm 1.9$ & $1.9 \pm 3.0$ & 0.21 & $2.1 \pm 0.6$ & $3.5 \pm 1.1$ & $1.4 \pm 1.2$ & 0.02 \\
\hline $\mathrm{LAD}_{\max }$ (Gy) & $48.6 \pm 1.5$ & $46.5 \pm 1.6$ & $2.2 \pm 2.1$ & 0.04 & $25.9 \pm 6.6$ & $34.5 \pm 6.1$ & $8.6 \pm 9.2$ & 0.07 \\
\hline $\begin{array}{l}\text { Ipsilateral-lung } \\
\mathrm{NTD}_{\text {mean }}\left(\mathrm{Gy}_{3}\right)\end{array}$ & $3.7 \pm 0.8$ & $0.3 \pm 0.8$ & $3.5 \pm 0.5$ & $<0.001$ & $1.4 \pm 0.5$ & $0.2 \pm 0.1$ & $1.1 \pm 0.2$ & $<0.001$ \\
\hline $\begin{array}{l}\text { Chest-wall } \\
V_{50 G y}\left(\mathrm{~cm}^{3}\right)\end{array}$ & $20 \pm 7$ & $2 \pm 1$ & $18 \pm 7$ & $<0.001$ & $3 \pm 2$ & $1 \pm 1$ & $2 \pm 2$ & 0.08 \\
\hline
\end{tabular}


Table 2: Comparison of cardiac doses according to superiority of patient position for WBI and PBI

\begin{tabular}{|c|c|c|c|c|c|c|c|c|}
\hline & \multicolumn{4}{|c|}{ Supine position better } & \multicolumn{4}{|c|}{ Prone position better } \\
\hline \multirow[t]{2}{*}{ WBI } & \multicolumn{4}{|l|}{$\mathrm{N}=8$} & \multicolumn{4}{|l|}{$\mathbf{N}=19$} \\
\hline & Supine & Prone & Difference & $\mathbf{p}$ & Supine & Prone & Difference & $p$ \\
\hline $\begin{array}{l}\text { Heart-NTD }{ }_{\text {mean }} \\
\left(\mathrm{Gy}_{3}\right)\end{array}$ & $0.7 \pm 0.1$ & $1.1 \pm 0.3$ & $0.5 \pm 0.2$ & 0.01 & $1.2 \pm 0.2$ & $0.8 \pm 0.1$ & $0.4 \pm 0.1$ & $<0.001$ \\
\hline $\begin{array}{l}\text { LAD-NTD } \text { mean } \\
\left(\mathrm{Gy}_{3}\right)\end{array}$ & $5.1 \pm 2.2$ & $13.5 \pm 3.2$ & $8.4 \pm 2.5$ & $<0.001$ & $14.6 \pm 2.4$ & $7.5 \pm 2.1$ & $7.0 \pm 2.1$ & $<0.001$ \\
\hline $\mathrm{LAD}_{\max }(\mathrm{Gy})$ & $45.1 \pm 4.7$ & $49.1 \pm 1.8$ & $3.9 \pm 3.3$ & 0.05 & $49.7 \pm 0.4$ & $44.9 \pm 1.9$ & $4.9 \pm 1.7$ & $<0.001$ \\
\hline \multirow[t]{2}{*}{ PBI } & \multicolumn{4}{|l|}{$\mathrm{N}=19$} & \multicolumn{4}{|l|}{$\mathrm{N}=7$} \\
\hline & Supine & Prone & Difference & $\mathbf{p}$ & Supine & Prone & Difference & $\mathbf{p}$ \\
\hline $\begin{array}{l}\text { Heart NTD }{ }_{\text {mean }} \\
\left(\mathrm{Gy}_{3}\right)\end{array}$ & $0.3 \pm 0.1$ & $0.5 \pm 0.1$ & $0.2 \pm 0.1$ & 0.002 & $0.4 \pm 0.1$ & $0.3 \pm 0.1$ & $0.2 \pm 0.1$ & 0.10 \\
\hline $\begin{array}{l}\text { LAD NTD }{ }_{\text {mean }} \\
\left(\mathrm{Gy}_{3}\right)\end{array}$ & $1.7 \pm 0.7$ & $4.6 \pm 1.4$ & $3.0 \pm 1.1$ & $<0.001$ & $3.4 \pm 1.4$ & $1.3 \pm 0.8$ & $2.1 \pm 1.4$ & 0.03 \\
\hline $\mathrm{LAD}_{\max }(\mathrm{Gy})$ & $19.0 \pm 7.6$ & $42.7 \pm 3.6$ & $23.7 \pm 6.5$ & $<0.001$ & $41.9 \pm 5.4$ & $14.3 \pm 12.7$ & $27.6 \pm 10.5$ & 0.003 \\
\hline
\end{tabular}




\section{Figure Captions}

Figure 1. Prone platform including polycarbonate centrepiece with aperture, polystyrene head and body supports, and polystyrene wedge to support contralateral breast

Figure 2. Distributions of patients by a) cup size and b) whole-breast clinical-target volume

Figure 3a-e. Box and whiskers plots displaying normal tissue dosimetry a) HeartNTD $D_{\text {mean }}$ b) LAD-NTD mean c) LAD $_{\max }$ (figures 3a-c include left-breast-affected women only, $n=30)$ d) Ipsilateral-lung $\operatorname{NTD}_{\text {mean }}(n=65)$ e) Chest-wall $V_{50 G y}$ ( $n=65)$. Black dots= outliers (numbers represent trial-numbers)

Figure 4. Relationship of breast-tissue (cyan-outline), heart (pink-outline), and leftanterior-descending coronary-artery (red-outline with cyan-bullseye) to chest-wall for: i) woman of cup-size $B$ and ii) woman of cup-size $F$ a) supine and b) prone

Figure 5. Mean difference in cardiac variables (supine minus prone) expressed by whole-breast clinical-target volume tertile for a) WBI and b) PBI. (Negative values= benefit of prone position) 


\section{Figure 1.}

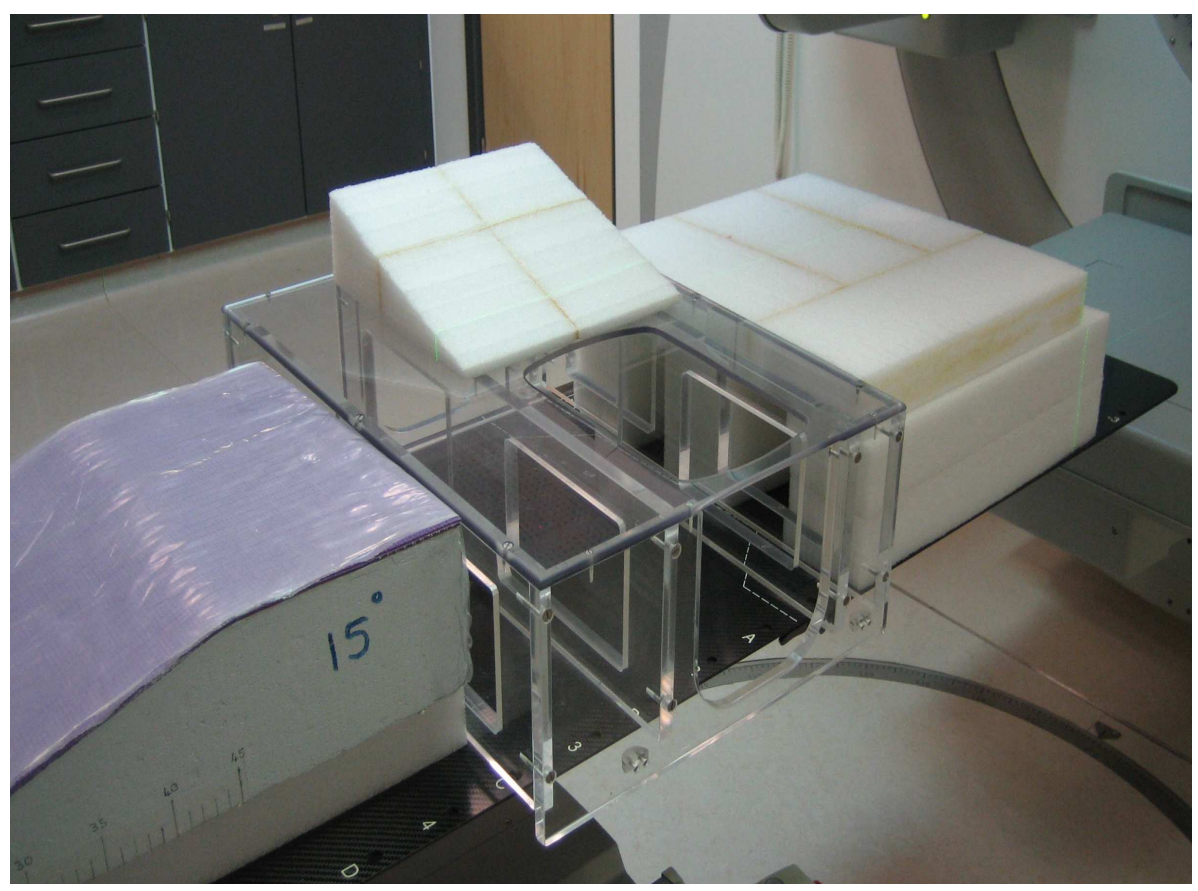


Figure 2.

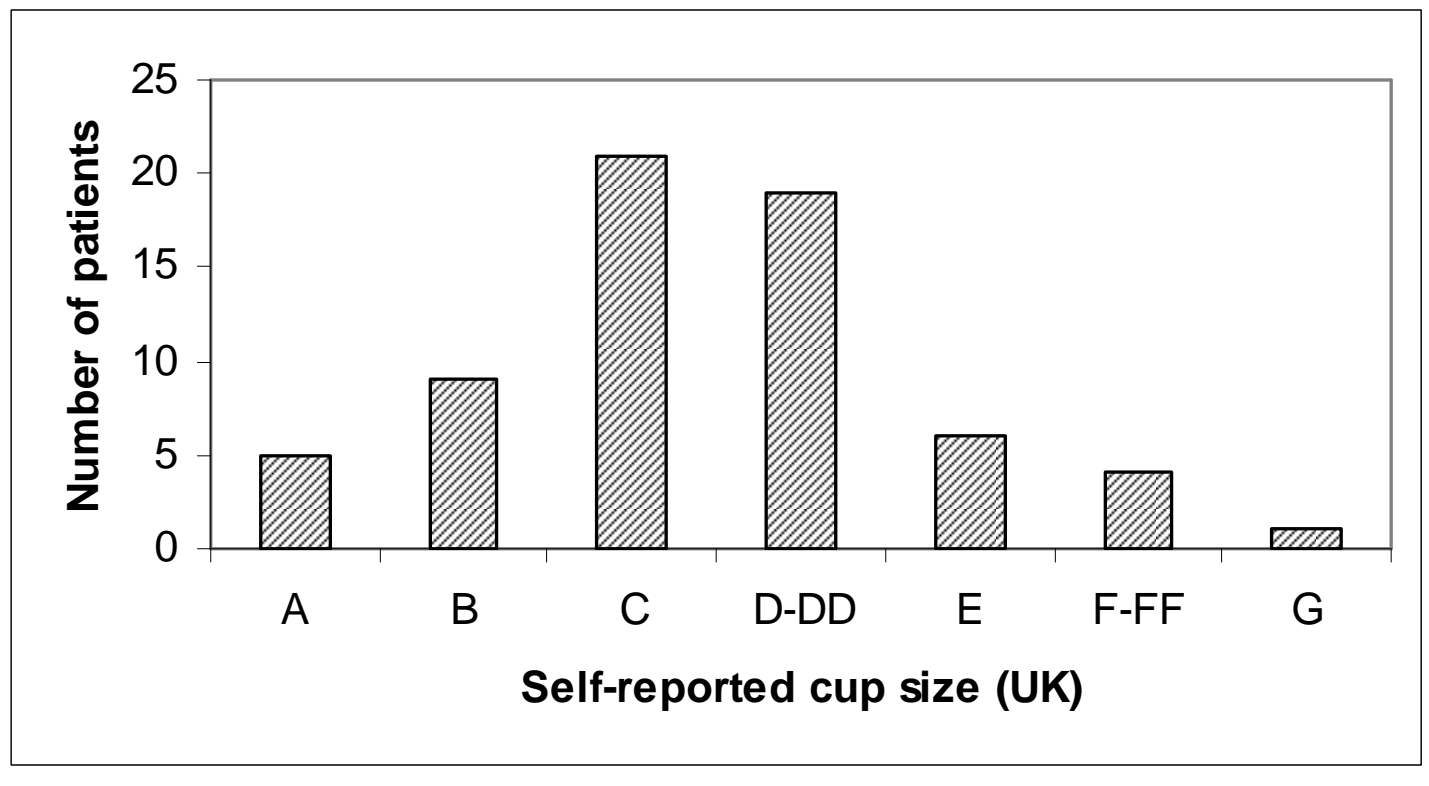

a

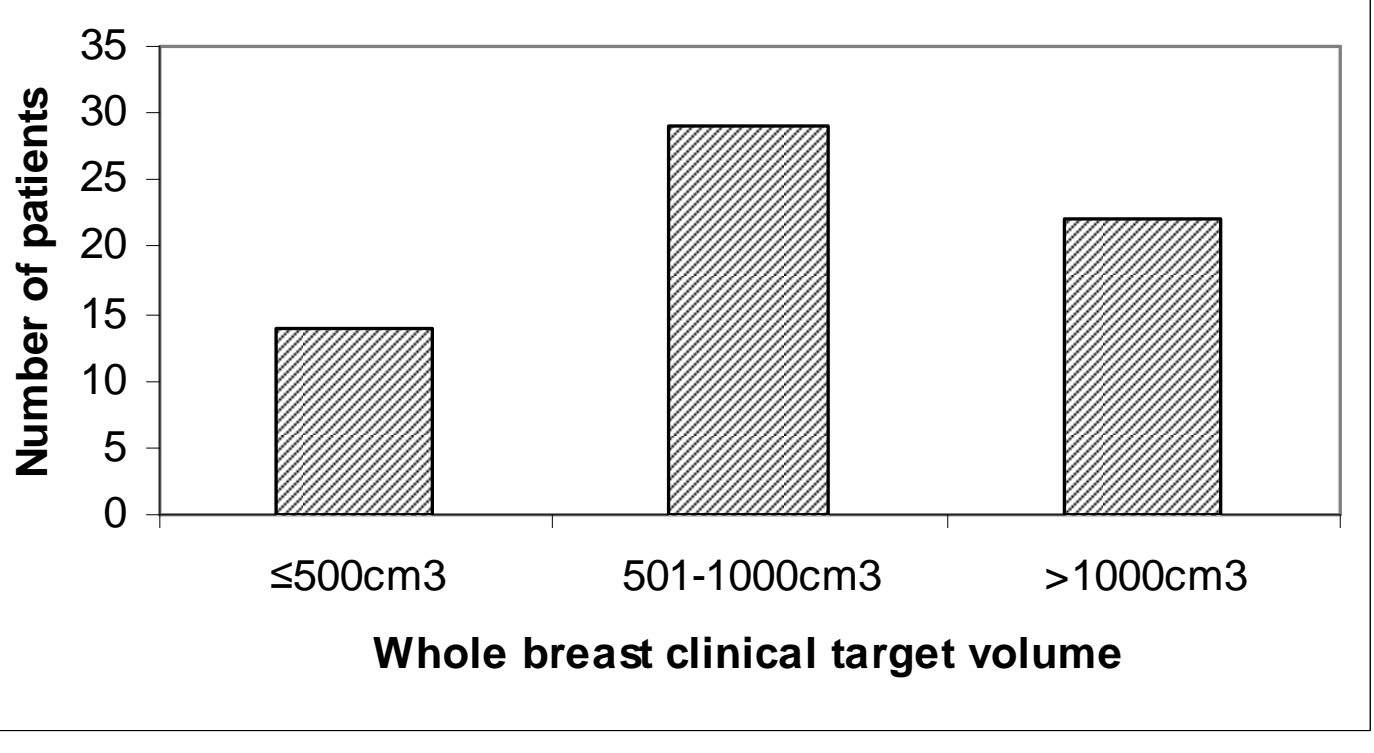


Figure 3.
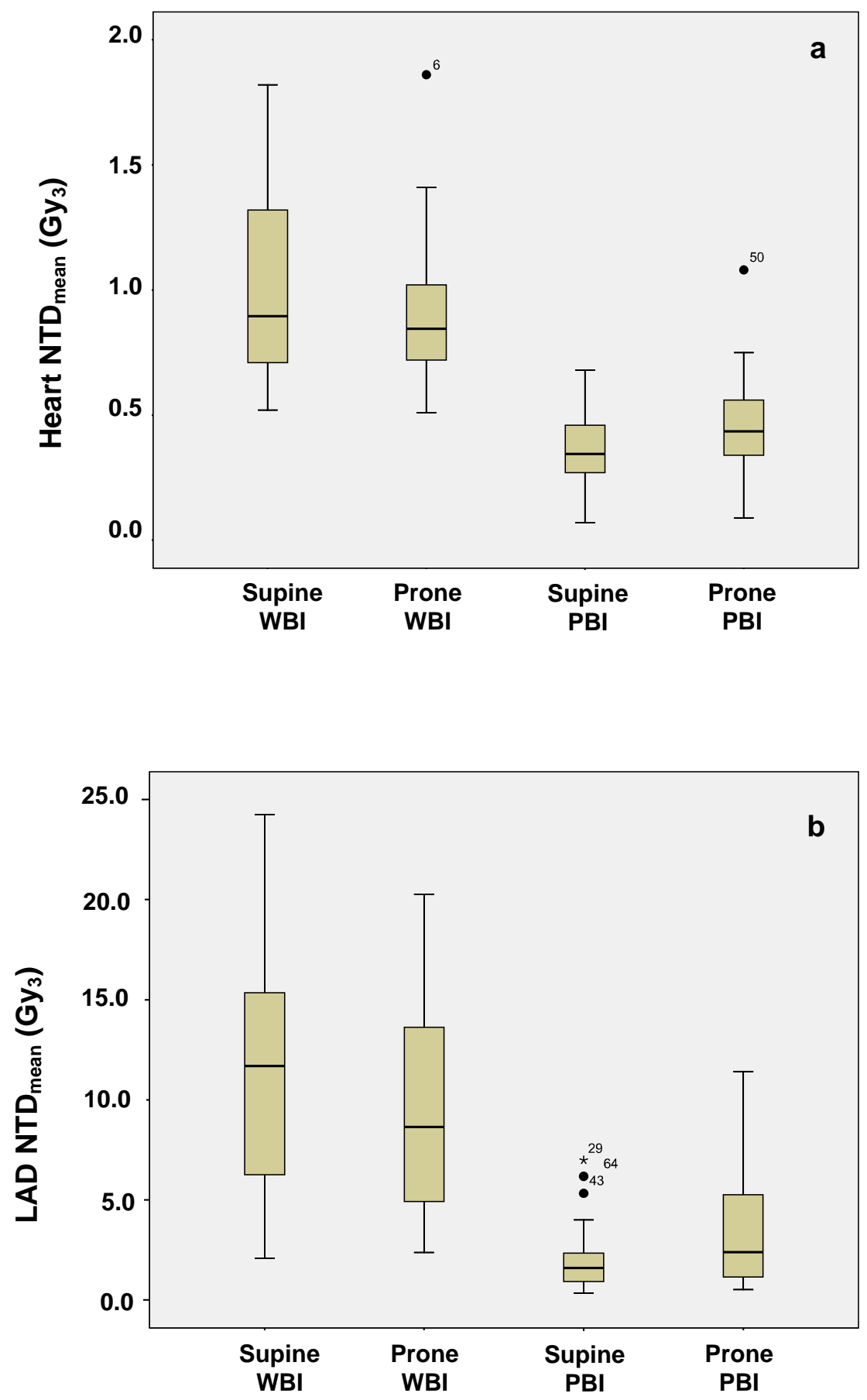
Chapter 6

Prone-supine dosimetry
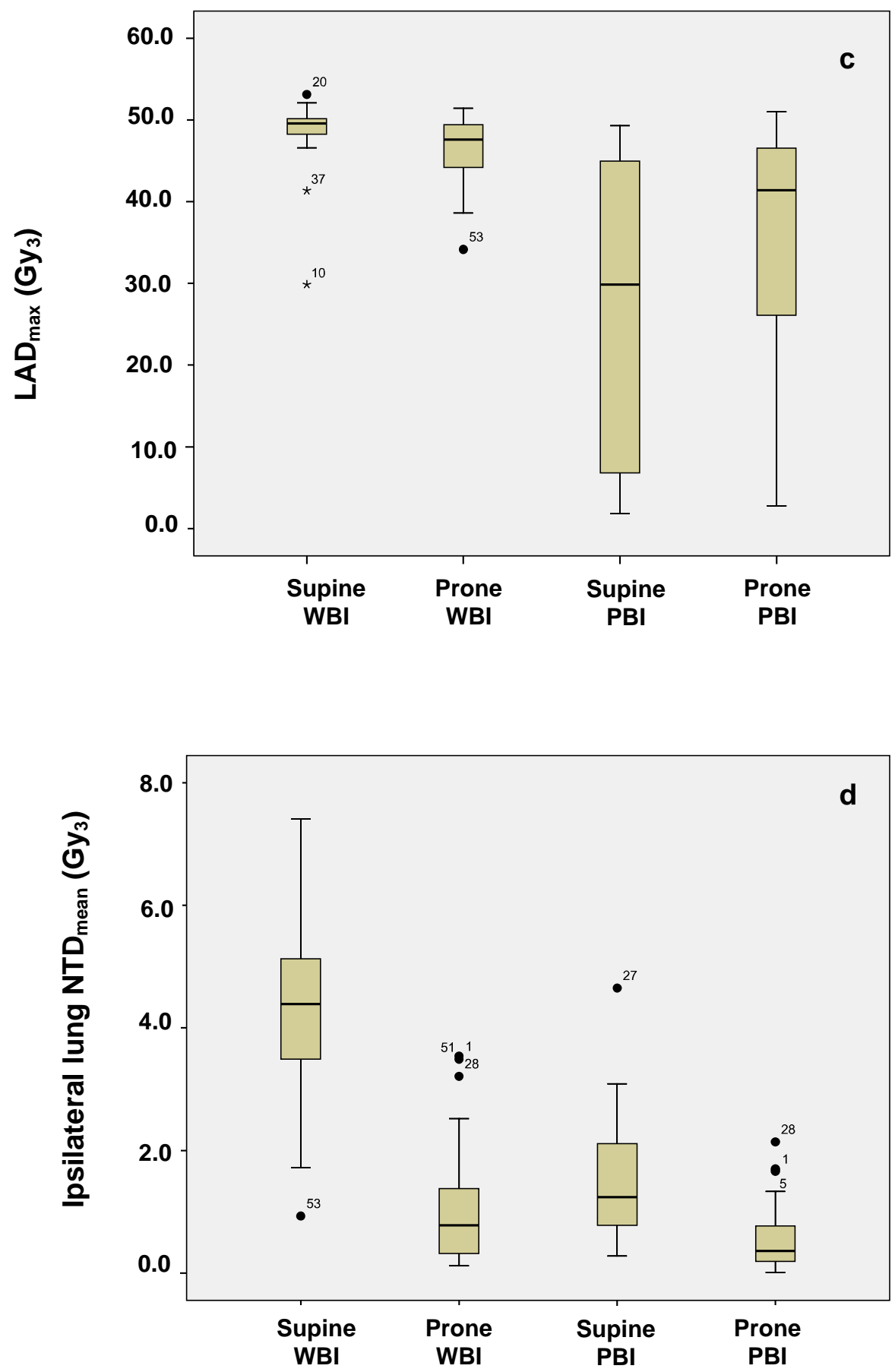
Chapter 6

Prone-supine dosimetry

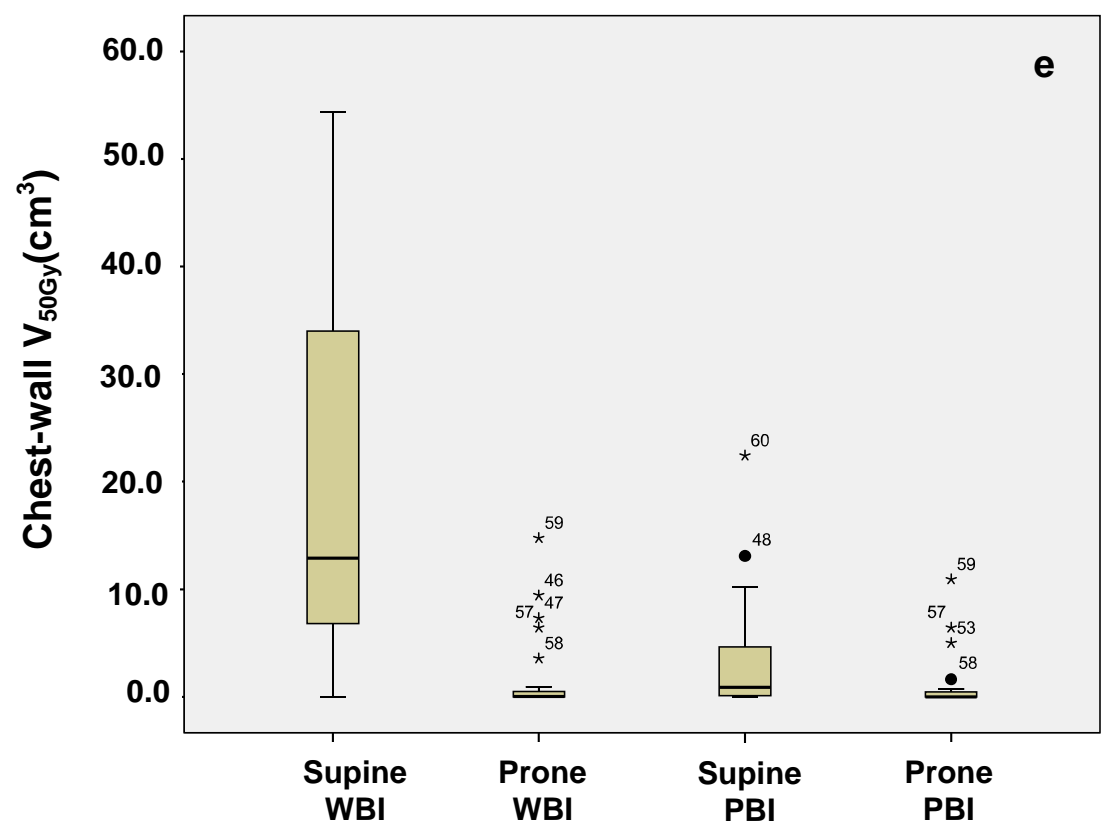


Figure 4.
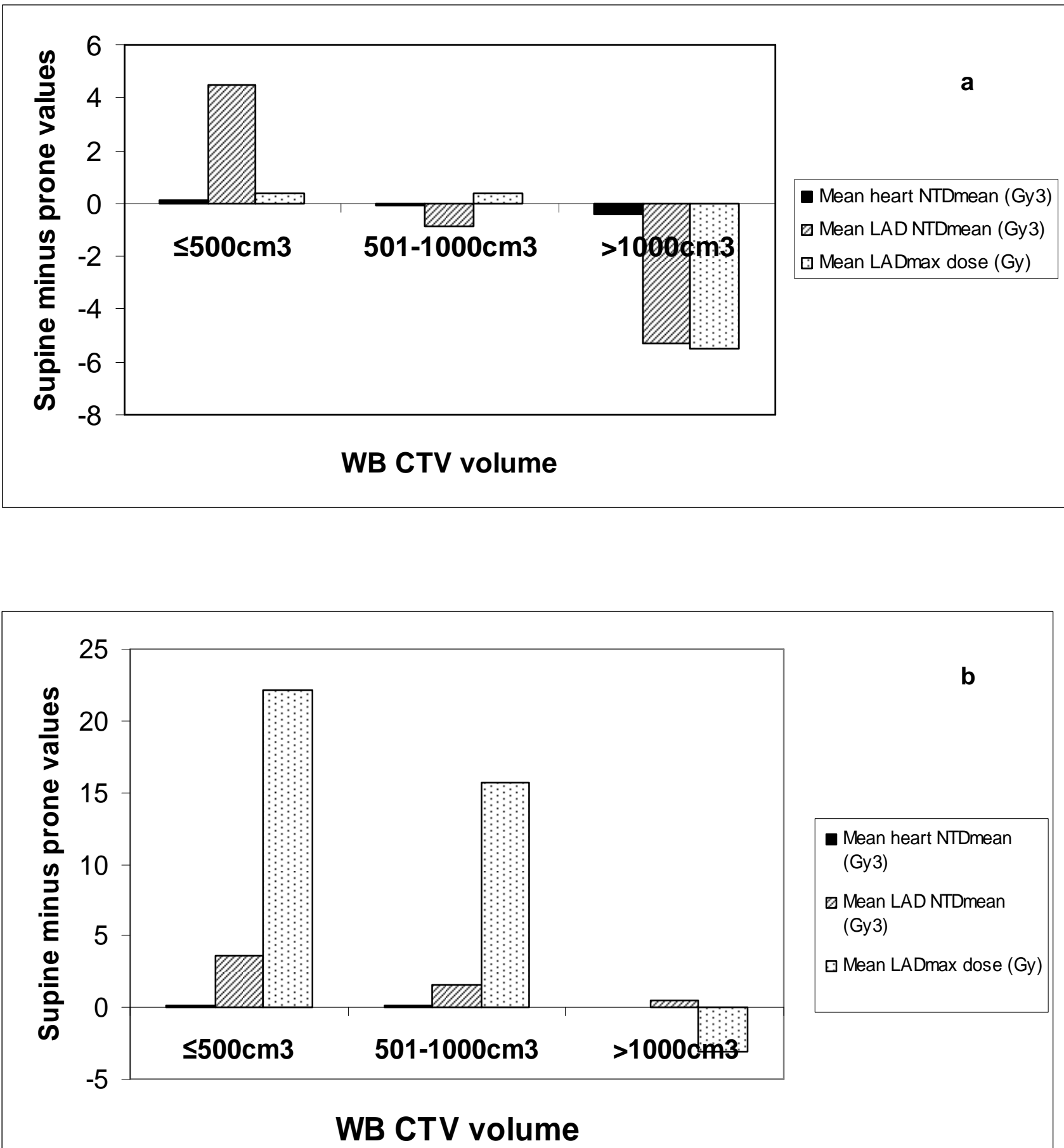

- Mean heart NTDmean (Gy3)

$\square$ Mean LAD NTDmean (Gy3)

$\square$ Mean LADmax dose (Gy) 
Chapter 6

Figure 5.

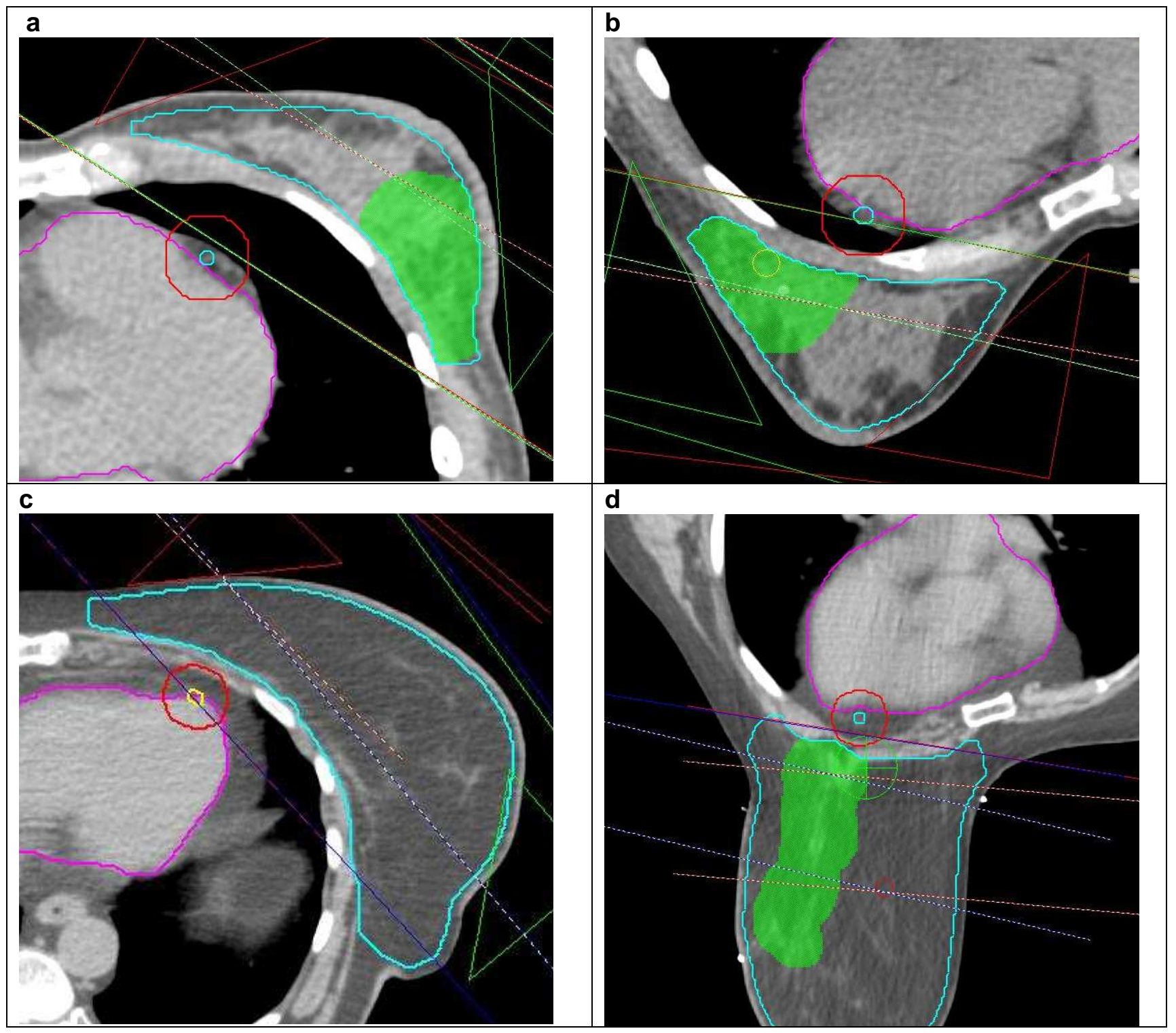

